\title{
Case studies of employers with exemplary early intervention and return to work practices
}

\author{
Christine Randall \\ School of Human Services and Social Work, Griffith University, Southport QLD 4222, Australia. c.randall@griffith.edu.au
}

Background: There is ample evidence that returning to suitable work is good for an injured worker's health and wellbeing. Evidence from the 2013 National Return to Work Survey shows a positive relationship between employers' treatment of injured workers and return to work outcomes.

Objectives: The case studies project aims to provide:

- employers with examples of practical solutions, practices or systems to improve return to work outcomes, and

- policy makers with a summary of key themes and best practice approaches to inform the development of policy and programs.

Methods: Organisations for the case studies will be shortlisted from recent Australian national return to work award winners and finalists. Key players within the organisations, including managers, supervisors, rehabilitation co-ordinators and recovered injured workers, will be interviewed to obtain information and attitudes on the early intervention and return to work approaches. An analysis of the case studies and a literature review on current best practice for early intervention and return to work will be conducted from which key themes and practices will be identified.

Findings: The project will produce two reports: case studies of six organisations' practices, and an analytical report on key findings and best practice for early intervention and return to work. The case studies will provide employers and workers published examples of practical approaches to improving return to work outcomes. The case studies also explore the roles and views of management, supervisors and injured workers. The analytical report will examine the case studies and report on key themes and best practice, providing policy makers and employers with an analysis of findings. The 2013 National Return to Work survey provides supporting evidence of the positive relationship between return to work outcomes and a range of variables related to the role of the employer and the workplace.

Conclusion: It is anticipated the case studies project will provide examples of practical approaches to improving early intervention and return to work outcomes, which other organisations may consider implementing. 